\title{
A REDAÇÃO DE VESTIBULAR: COMO ALUNOS VESTIBULANDOS PODEM MARCAR SUA "PRESENÇA" NOS TEXTOS
}

\author{
Jandira Pilar
}

\section{INTRODUÇÃO}

No contexto atual, quando a redação de vestibular é motivo de preocupação para alunos que prestam o concurso vestibular, torna-se extremamente necessário que nós, que ensinamos a redação voltada especificamente para esse concurso, façamos uma reflexão sobre este tema. Afinal, a prática tem demonstrado que os livros didáticos utilizados por nós para o ensino/aprendizagem desse tipo de texto não têm sido suficientes para orientar um trabalho em nossas escolas que possibilite ao aluno preparar-se para a prova de redação no referido concurso. Isso pode ser percebido pelo grande número de alunos vestibulandos que procuram um trabalho de redação fora do âmbito da escola, seja em cursinhos pré-vestibulares, seja na forma de trabalhos particularizados de produção textual.

Sem, no momento, discutir a idéia errônea que, muitas vezes, perpassa o trabalho de produção textual e tampouco apresentar considerações sobre o processo de ensino/aprendizagem de redação em nossas escolas, gostaria de discutir uma questão que tem incomodado, de maneira bastante particular, muitos alunos que necessitam realizar a prova de redação: o posicionamento do autor na redação de vestibular. Para ancorar essa discussão, serão utilizados alguns trechos de redações Nota Dez, produzidas no concurso vestibular da Universidade Federal do Rio Grande do Sul, no ano de 1997.

\section{A NECESSIDADE DE POSICIONAMENTO NAS REDAÇÕES DE VESTIBULAR}

Nossa experiência na escola de ensino médio e em cursos pré-vestibulares tem demonstrado que os alunos que se preparam para o concurso vestibular, ao produzirem seus textos, priorizam a estrutura formal gramatical. Ao agir assim, eles não se inserem na discussão proposta pela tarefa da prova, limitando-se "a fazerem cópias disfarçadas dos textos dos outros, sem assegurarem sua entrada no jogo que Ihes permitiria exercerem a sua função-autor" (Carmagnani, 1998, p.21). Isso é comprovado pelas redações produzidas por alunos pré-vestibulandos em nossas aulas. Um número bastante significativo delas apresenta aspectos positivos e 
negativos do tema abordado, sem configurar uma tese que possa sustentar a discussão sobre o tema. Além disso, mesmo que a tarefa oportunize a eles usarem experiências pessoais ou empregarem a primeira pessoa do singular para discorrerem sobre o tema, é muito raro encontrar esses elementos em redações produzidas por alunos vestibulandos.

No entanto, levando em conta tarefas propostas em provas de redação de vestibulares, podemos dizer que a primeira condição para a produção de um texto satisfatório é a inserção do candidato na situação proposta como tema, que é, por sua vez, fator essencial para a elaboração da tese. Conforme podemos observar em tarefas propostas, os concursos vestibulares dos últimos anos têm solicitado o posicionamento do aluno em relação ao tema e a apresentação de argumentos consistentes para defender esse posicionamento.

$\mathrm{Na}$ tarefa demonstrada abaixo, por exemplo, os candidatos a uma vaga no concurso vestibular da UFRGS devem apresentar em seus textos uma tese central que responda à questão proposta: "Que reformulações deve haver no concurso vestibular da UFRGS?'. 
Há muitas discussões sobre a reformulação do Concurso vestibular. Alguns propõem sua extinção sumária; outros defendem que seja substituído por concursos isolados, para as diversas carreiras acadêmicas; outros ainda advogam sua reformulação parcial, sugerindo pequenos ajustes na forma atual ou propondo a exigência de questões apenas discursivas em todas as provas.

Como membro da comunidade na qual esse concurso é realizado, você certamente tem muito a dizer sobre a adequação do vestibular ao tipo de candidato que normalmente presta os exames. Além disso, ainda que jamais se tenha preocupado antes com o vestibular, você está, nesse momento envolvido com ele. Você acha que o vestibular, na sua forma atual, seleciona de maneira eficaz os futuros alunos da UFRGS, valorizando adequadamente seus conhecimentos, habilidades e aptidões? Ou você acredita que possa haver uma maneira melhor de fazê-lo? Lembre-se de que qualquer proposta relativa ao vestibular, se eventualmente adotada pela Universidade teria reflexos extraordinários na sociedade como um todo, e não é ao seu bem individual que a Universidade visa, e sim ao da coletividade.

Pois bem: sua redação deverá desenvolver sua resposta à questão "que reformulações deve haver no concurso vestibular da UFRGS"?. Para isso, parta de sua experiência pessoal, enuncie a(s) reformulação (ões) que considera necessária (s) e apresente motivos para sua proposta. Desde logo, fique claro que, para fins de atribuição de nota, não será avaliado o mérito de suas opiniões, mas sim sua capacidade de redigir um texto correto e articulado sobre o tema.

Lembre-se de que você está sendo solicitado a redigir uma dissertação, texto que se caracteriza por um esforço de reflexão racional em torno de um tema. Valha-se de sua experiência como ponto de partida, mas apresente-a articulada em um texto argumentativo, organizado dissertativamente.

A dissertação deve ter a extensão mínima de 30 linhas e máxima de 60 considerando letra de tamanho regular. Inicialmente, utilize a folha de rascunho e, depois, passe a limpo na folha de redação, sem rasuras e com letra legível, o que você escreveu. Utilize caneta; lápis, apenas no rascunho.

Quadro 1 - Prova de Redação do Concurso Vestibular da Universidade Federal do Rio Grande do Sul/UFRGS/1997.

Podemos dizer que a "resposta" dos alunos-candidatos à tarefa da prova implica uma tomada de posição, de inserção deles no problema proposto. Assim, a resposta deve configurar uma tese que indicará qual (ou quais) reformulação(ões) é (são) necessária(s) no concurso vestibular da UFRGS.

Não se pode esquecer, porém, que as teses apresentadas pelos alunos, estão vinculadas à avaliação do problema tratado na prova, isto é, à necessidade de alunos em final de ensino médio prestarem o concurso vestibular. Tanto a avaliação desse problema quanto a tese central apresentada pelos alunos podem ser analisadas por marcas lingüísticas como as que seguem. 


\section{AS MARCAS LINGÜÍSTICAS QUE INDICAM O POSICIONAMENTO DOS}

ALUNOS

Entre as marcas lingüísticas empregadas nas redações analisadas identificamos palavras que se constituem em índices avaliativos, experiências pessoais, verbos em primeira pessoa do singular, verbos em primeira pessoa do plural e recursos de modalidade.

Os índices avaliativos permitiram aos candidatos usarem suas impressões para avaliarem o problema apresentado no tema, conforme podemos ver nos fragmentos que seguem:

1. (Redação 6, §1) A cada ano, milhares de jovens se entregam de corpo e alma à disputa acirrada e tensa que é o vestibular da UFRGS.

2. (Redação 1, §1e 2) Porém, para tal precisará, antes, ser bem sucedido no vestibular: a maratona de cerca de trezentos testes que selecionam os futuros acadêmicos da UFRGS. O fato de você estar em uma sala com mais vinte estudantes, todos seus concorrentes diretos é realmente estressante.

3. (Redação 3, §1 e 5) Hoje, estamos enfrentando mais uma batalha em nossa vida. Talvez não seja uma simples batalha, mas sim uma guerra. Estão sendo feitas milhares de redações, que além de julgar se cada autor tem ou não condições de entrar na faculdade demonstra que a UFRGS está a fim de por (sic) um fim ao monstro do vestibular.

4. (Redação 9, §1) Tensão, nervosismo, colapsos nervosos... é assim que a maioria dos jovens encara o vestibular: um verdadeiro martírio. $E$ todos os anos, nesta época, milhares de pais e amigos se vêem envolvidos na agonia pela qual passa o vestibulando.

Conforme podemos ver pelos fragmentos, palavras como "disputa acirrada e tensa", "maratona", "batalha", "guerra", "monstro", "agonia" foram utilizadas pelos alunos para avaliar o concurso vestibular. Essas palavras são índices avaliativos Vande Kopple (1985), que demonstram o envolvimento dos candidatos com o tema proposto na prova. No caso das redações de vestibulandos, essas palavras permitiram aos alunos fazer avaliações do conteúdo proposicional do texto em termos de conceitos "bom"e "ruim", ou "positivo" e "negativo". Eles demonstraram, assim, sua opinião sobre o problema discutido, emitindo o seu juízo de valor em relação ao assunto. A autoria, aqui, está relacionada à presentificação do autor no texto e ao seu comprometimento com o tema que aborda. 
Outra maneira de alunos vestibulandos marcarem sua presença é o uso de experiências pessoais, conforme podemos ver nos fragmentos abaixo:

1. Eu já vivenciei tal experiência e sei que não é fácil realizar uma prova de vestibular.

2. (Redação 5, §2) Eu, por exemplo, sempre fui muito dedicada aos estudos, passando horas, no meu quarto, ou na biblioteca da escola estudando. Sempre consciente de que um bom preparo na escola seria o caminho que contribuiria, em grande parte, para o ingresso na universidade, desde cedo me preocupei com o vestibular. Mesmo assim, confesso não ter conseguido dormir nas noites que antecederam o concurso e, apesar de ter estudado[CF1] em um ótimo colégio e obtido boas notas, senti-me insegura diante do concorrido vestibular para Direito.

Como podemos perceber, as experiências pessoais dos alunos foram utilizadas para justificar seus posicionamentos e, com isso, argumentarem sobre a validade de suas opiniões. Assim, os alunos que prestaram o concurso vestibular na UFRGS, em 1997, puderam propor reformulações no concurso vestibular levando em conta as suas experiências como alunos vestibulandos.

Da mesma maneira, verbos nas primeiras pessoas do singular e do plural indicam a maneira como o autor presentifica-se no texto e a relação que ele estabelece com seu leitor, conforme podemos perceber nos fragmentos abaixo:

1. (Redação 2, §4) Acredito que, enquanto o vestibular exigir conhecimentos previsíveis, com questões profetizadas pelos cursinhos, continuaremos com alunos cujo conceito de aprovação no vestibular significa a alegria de nunca mais precisarem enxergarem (sic) logarítimos.

2. (Redação $3, \S 3$ ) Não podemos culpar a UFRGS pelo caos do nosso sistema educacional. Não temos condições de fazer como os E.U.A. ou outros países desenvolvidos onde o aluno que apresentar o melhor currículo escolar tem vaga garantida nas melhores universidades do mundo.

Consideramos também que o emprego de verbos em primeira pessoa do plural denota a tentativa de o autor compartilhar com o leitor a responsabilidade do problema apresentado no texto. Segundo Clark \& Ivanic (1997), escritores dos mais diferentes gêneros freqüentemente empregam o "nós" para simular que ambos (escritor e leitor) têm o mesmo posicionamento. Segundo as autoras, essa é uma maneira de escritores conquistarem seus leitores para que participem de seu posicionamento. Para elas, se escritores estão escrevendo para persuadir um grupo de leitores resistentes sobre 
suas visões, eles necessitam tratar o diálogo com seus leitores diferentemente de uma audiência que aceite suas idéias.

1. (Redação 1, §4) Enfim, acho que o vestibular não pode ser extinguido, já que a procura por vagas é bem maior que a oferta. Porém, mudanças devem ser feitas a fim de que se avalie o grau de aprendizagem do estudante durante toda sua vida escolar e não apenas o que ele aprendeu no "cursinho". Só assim garantiremos universitários e profissionais competentes.

2. (Redação 3, §5) É plenamente possível reformular o Vestibular, basta que todos nós pensamos (sic) juntos desde o reitor até o aluno, até chegar a uma conclusão.

3. (Redação 2, §4) Acredito que, enquanto o vestibular exigir conhecimentos previsíveis, com questões profetizadas pelos cursinhos, continuaremos com alunos cujo conceito de aprovação no vestibular significa a alegria de nunca mais precisarem enxergarem (sic) logarítimos.

Podemos dizer ainda que os alunos que prestaram o concurso vestibular na UFRGS demonstraram levar em conta quem são os leitores dos textos. Alguns trechos das redações que transmitem críticas ao sistema educacional e que, ao mesmo tempo, modalizam a linguagem no sentido de não impor a responsabilidade à UFRGS, comprovaram que o uso da linguagem está relacionado ao objetivo comunicativo e à relação com a audiência-alvo.

Outra maneira de alunos relacionarem-se com seus leitores é o uso de recursos de modalidade. Os alunos que prestaram concurso na UFRGS em 1997, por exemplo, engajaram-se no assunto tratado, assumindo com maior ou menor certeza as suas afirmações. Ao usarem as palavras "dever", "precisar", "necessitar", "permitir" nas redações, ou ainda verbos modais ou advérbios que estabelecem a mesma relação de obrigatoriedade, de necessidade, de permissão como "realmente", "necessariamente", "obrigatoriamente", recorreram à modalidade deôntica para demonstrar até que ponto acreditam que as proposições que defendem são verdadeiras. Segundo Halliday (1994), a modalidade deôntica apresenta-se numa escala que varia entre o que é obrigatório, proibido, permitido ou facultativo fazer. Essa modalidade é exemplificada nos fragmentos abaixo. 
1. (Redação 1, §2) Os candidatos deveriam ser distribuídos em ordem alfabética nas escolas, desconsiderando-se o curso a que concorrem, o que amenizaria um pouco a competição.

2. (Redação 3, §1) Essa guerra injusta precisa ser modificada para não trazer mais tantas decepções a quem não consegue vencê-la.

3. (Redação 4, §2) Possíveis mudanças no concurso vestibular devem, em primeiro lugar, respeitar a comunidade em que o mesmo insere-se.

4. (Redação 6, §) E, para que tal sonho se concretize, é necessário que antes se passe por uma verdadeira guerra chamada vestibular.

5.(Redação 8, §3) As matérias avaliadas deveriam ser escolhidas de acordo com o curso e as questões ser(sic) somente dissertativas.

6. (Redação 9, §4) A reformulação do vestibular deve ser discutida por todos os setores da sociedade, pois todos se vêem, diariamente, indiretamente envolvidos com profissionais medíocres e incompetentes, frutos prováveis de um sistema incompletde seleção para a universidade.

Como podemos perceber, com o uso desses recursos de modalização, escritores vão através de comandos, ofertas e sugestões estabelecendo relações com o interlocutor, no sentido de assegurar que ele compartilhe da necessidade das sugestões propostas.

Outros alunos, no entanto, preferiram manifestar sua opinião utilizando a modalidade epistêmica, evitando, assim, impor explicitamente sua opinião. Estudos têm demonstrado que palavras como "certamente", "provavelmente" e "possivelmente", empregadas nos textos, expressaram a variação entre a probabilidade e a usualidade, através de graus intermediários de possibilidade de as asserções serem verdadeiras (conforme Rebelo, 1999). Nas redações analisadas, o grau da usualidade é dado por expressões como "freqüentemente", "usualmente" e “algumas vezes” (Halliday, 1994).

\section{CONSIDERAÇÕES FINAIS}

A intenção deste trabalho foi tecer algumas considerações sobre as marcas lingüísticas que evidenciam a presença de alunos vestibulandos nas redações no sentido de proporcionar uma reflexão sobre o tema. Se a análise dos trechos das redações produzidas pelos alunos que realizaram o concurso na UFRGS, em 1997, revelou que alunos que têm seus textos considerados satisfatórios utilizam experiências pessoais, índices avaliativos, verbos em primeira pessoa do singular e 
do plural, é importante que os incentivemos a inserirem-se nos temas discutidos, analisando-os a partir de suas expectativas, de sua visão pessoal, sem a necessidade de manterem o "distanciamento" tão comum em textos de vestibulandos. Quem sabe assim, eles possam legitimar seus posicionamentos sem empregar "fórmulas prontas" e desgastadas que, muitas vezes, apenas os atrapalham na produção do texto.

Se à escola cabe oferecer condições para que os alunos ocupem o seu lugar social, é pertinente que levemos em conta a sua história de vida, seus desejos e aspirações ao trabalharmos a redação. Dessa maneira, quem sabe, eles poderão mais facilmente produzirem textos mais satisfatórios e adequados à tarefa proposta.

\section{BIBLIOGRAFIA}

CARMAGNANI, A. M. G. Da reprodução para a autoria: uma mudança possível. Revista Letras Santa Maria, no 17. p. 15-25. Santa Maria: Universidade Federal de Santa Maria. 1998.

CLARK, R.; Ivanic, R. The politics of writing. London: Routledge.1997.

HALLIDAY, M. A. K. An introduction to funcional grammar. London:

Edward Arnold, 1994.

REBELO, N. Análise do processo persuasivo no gênero editorial. Santa Maria: UFSM. 1999. Dissertação (Mestrado em Letras) - Universidade Federal de Santa Maria, $135 \mathrm{p}$.

UNIVERSIDADE FEDERAL do RIO GRANDE do SUL, Manual do Avaliador de Redações do Concurso Vestibular, 1999. COPERSO. UFRGS. Porto Alegre.

UNIVERSIDADE FEDERAL do RIO GRANDE do SUL, Prova do Concurso Vestibular, 1997. COPERSO. UFRGS. Porto Alegre.

VANDE KOPPLE, W. J. Some exploratory discourse on metadiscourse. College Composition and Communication. v. 1. № 36. 1985, p. 82-93. 